\title{
An Implementation of a Twelve Sectors Direct Torque Control Strategy of Induction Machine using DSPACE TMS 320F2812
}

\author{
Ouboubker Lahcen, \\ Khafallah Mohamed, \\ Essaadi Mouna, \\ Lamterkati Jawad \\ Hassan II University - ENSEM \\ Casablanca, Morocco
}

\author{
Chaikhy Hamid \\ Chouaib Doukkali University \\ Laboratory of Engineering \\ Science and Energy (LabSIPE) \\ ENSA, El Jadida, Morocco
}

\author{
Elafia Aziz \\ Hassan II University-ENSAM, \\ Casablanca, Morocco
}

\begin{abstract}
this paper presents an experimental implementation of a new direct torque control strategy of induction machine called twelve sectors direct torque control strategy (12_DTC) using DSPACE TMS 320F2812.The aim of this work is to give an experimental performance analysis of 12_DTC in term of torque, currents distortions and stator flux, to validate simulation results obtained in previous works.
\end{abstract}

\section{Keywords}

12_DTC, DSPACE TMS 320F2812 torque, stator flux, currents distortions, experimental performance analysis

\section{INTRODUCTION}

Traditionally, variable speed electric machines were based on DC motors, since the magnetic flux and torque are easily controlled by the stator and rotor current, respectively [1]. For the last two decades, DC motors was replaced by AC motors. Induction Machine (IM) is one of the robust AC motors that have been widely used in industry. However, due to their highly coupled non-linear structure, a high performance control of IM is a challenging problem [2]. During the last decade, a new control method called DTC has been created. DTC is characterized by his simple implementation and robustness. However, C_DTC has some disadvantages compared with new DTC strategies, like a slow response in both starts up and changes in either flux or torque [3] also the distortions are one of their main drawbacks. Different solutions have been proposed to overcome the mentioned drawbacks, 12_DTC [3]. The aim of this paper is to validate simulation results by presenting experimental results and give an analysis of the 12_DTC, to figure out the advantages and disadvantages of this strategy and find out new way to improve 12_DTC.

\section{PRINCIPE OF 12_DTC}

Since M. Depenbrock and I. Takahashi proposed DTC for IM in the middle of 1980's, more than decade has passed. It is getting more and more popular nowadays. The instantaneous values of the stator flux and torque are calculated from stator variable by using a closed loop estimator [4]. As shown in Fig. 1, stator flux and torque can be controlled directly and independently by properly selecting the inverter switching configuration.

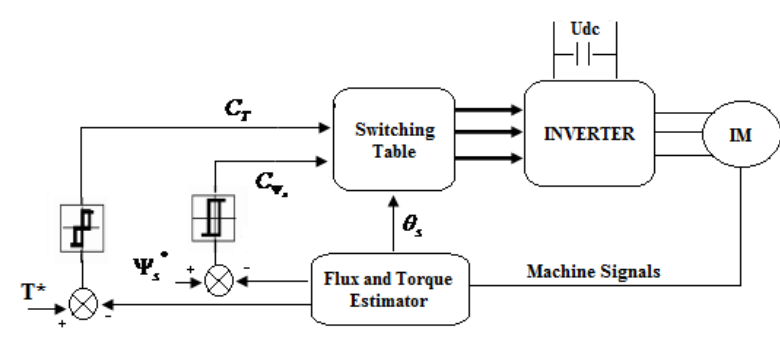

Fig. 1: block diagram of the DTC control technique

By using a $\alpha-\beta$ stationary stator reference frame, the stator flux linkage $\psi_{\mathrm{s}}$ and electromagnetic torque are calculating by using:

$\psi_{s}=\sqrt{\psi_{\alpha s}{ }^{2}+\psi_{\beta s}{ }^{2}}$

Where:

$\psi_{\alpha s}=\int_{0}^{t}\left(\mathrm{~V}_{\alpha s}-\mathrm{R}_{s} \mathrm{I}_{\alpha s}\right) d t$

$\psi_{\beta s}=\int_{0}^{t}\left(\mathrm{~V}_{\beta s}-\mathrm{R}_{s} \mathrm{I}_{\beta s}\right) d t$

The angle $\theta_{\mathrm{s}}$ is equal to:

$\theta_{s}=\tan ^{-1}\left(\frac{\psi_{\beta s}}{\psi_{\alpha s}}\right)$

$T=p\left[\psi_{\alpha s} \mathrm{I}_{\beta s}-\psi_{\beta s} \mathrm{I}_{\alpha s}\right]$

The block diagram of the classical DTC technique stills the same for the 12_DTC [6]. In fact, for both techniques each stator voltage has an effect on the flux and torque. When the stator flux is in sector $S_{i}$, the vectors $V_{i+1}$ or $V_{i-1}$ are selected to increase its amplitude, and $V_{i+2}$ or $V_{i-2}$ to decrease it. However $V_{i+1}$ or $V_{i+2}$ increase the torque and $V_{i-1}$ or $V_{i-2}$ decrease it. Tab. 1 and Fig.2 presents the effect of stator voltage in flux and torque for the first and the twelfth sector. 
Table 1. Switching table of the 12_DTC

\begin{tabular}{|c|c|c|c|}
\cline { 3 - 4 } \multicolumn{2}{c|}{} & Augmentation & Diminution \\
\hline \multirow{2}{*}{ S12 } & Flux & $\overline{\mathrm{V}}_{1}, \overline{\mathrm{V}}_{2}, \overline{\mathrm{V}}_{6}$ & $\overline{\mathrm{V}}_{3}, \overline{\mathrm{V}}_{4}, \overline{\mathrm{V}}_{5}$ \\
\cline { 2 - 4 } & Torque & $\overline{\mathrm{V}}_{1}, \overline{\mathrm{V}}_{2}, \overline{\mathrm{V}}_{3}$ & $\overline{\mathrm{V}}_{4}, \overline{\mathrm{V}}_{5}, \overline{\mathrm{V}}_{6}$ \\
\hline \multirow{2}{*}{ S1 } & Flux & $\overline{\mathrm{V}}_{1}, \overline{\mathrm{V}}_{2}, \overline{\mathrm{V}}_{6}$ & $\overline{\mathrm{V}}_{3}, \overline{\mathrm{V}}_{4}, \overline{\mathrm{V}}_{5}$ \\
\cline { 2 - 4 } & Torque & $\overline{\mathrm{V}}_{2}, \overline{\mathrm{V}}_{2}, \overline{\mathrm{V}}_{4}$ & $\overline{\mathrm{V}}_{5}, \overline{\mathrm{V}}_{6}, \overline{\mathrm{V}}_{1}$ \\
\hline
\end{tabular}

It's clearly noticed in Tab. 1 that all the six vectors are used disappearing all ambiguities. In fact, in C_DTC there are two states per sector $i$ that present a torque ambiguity which are $\bar{V}_{i}$ and $\bar{V}_{i+1}$. Therefore, they are never used. In a same way, in M_DTC there are two states per sector $i$ that introduce flux ambiguity which are $\bar{V}_{i+2}$ and $\bar{V}_{i+5}$, so they are never used either. If the stator flux locus is divided into twelve sectors [7] instead of just six, all six active states will be used per sector and the problem of ambiguity of both flux and torque will be solved.

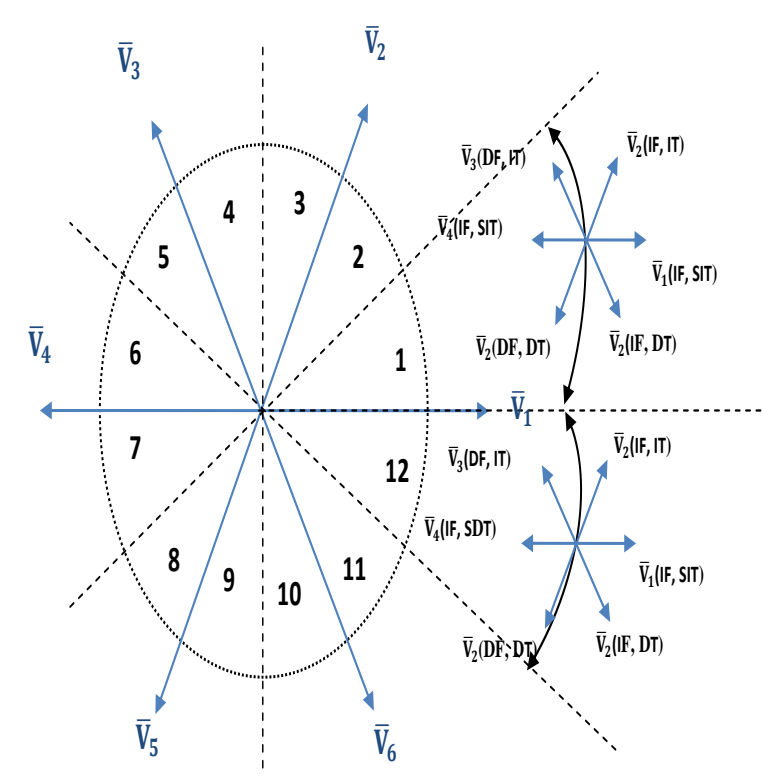

Fig.2: Twelve sectors modified DTC (12_DTC)

IT/DT/IF/DF/SIT/SDT: Increase Torque/ Decrease torque/Increase flux/decrease Flux/Small increase of Torque/Small decrease of torque

Switching table of the 12_DTC becomes Tab.2. It is obvious that $\mathrm{V} 1$ will produce a large increase in flux and a small increase in torque in sector $\mathrm{S}_{12}$. On the contrary, $\mathrm{V}_{2}$ will increase the torque in large proportion and the flux in a small one. It is reasonable to deduce that the torque error should be divided in the number of intervals that later on will be measured. Therefore, the hysteresis block should have four hysteresis levels as it suggested in Fig.3

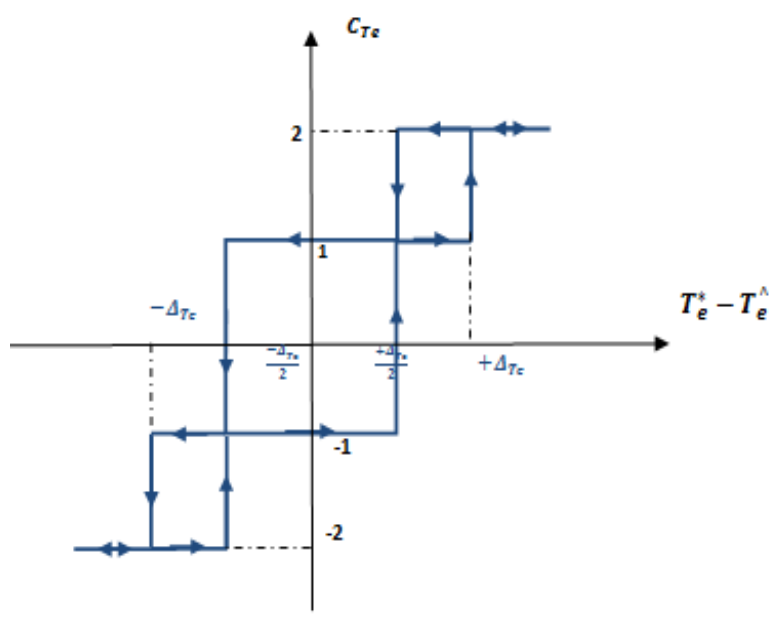

Fig.3: Four level hysteresis corrector

Table 2. Switching table of the 12_DTC

\begin{tabular}{|c|c|c|c|c|c|c|c|c|c|c|c|c|c|}
\hline \multicolumn{2}{|c|}{ Sector } & \multirow{2}{*}{1} & \multirow{2}{*}{2} & \multirow[t]{2}{*}{3} & \multirow[t]{2}{*}{4} & \multirow[t]{2}{*}{5} & \multirow[t]{2}{*}{6} & \multirow[t]{2}{*}{7} & \multirow[t]{2}{*}{8} & \multirow[t]{2}{*}{9} & \multirow{2}{*}{10} & & \multirow{2}{*}{$\begin{array}{l}1 \\
2\end{array}$} \\
\hline$C_{\psi s}$ & $C_{T e}$ & & & & & & & & & & & & \\
\hline \multirow{4}{*}{1} & 2 & $\overline{\mathrm{V}}_{2}$ & $\overline{\mathrm{V}}_{3}$ & $\overline{\mathrm{V}}_{3}$ & $\overline{\mathrm{V}}_{4}$ & $\overline{\mathrm{V}}_{4}$ & $\overline{\mathrm{V}}_{5}$ & $\overline{\mathrm{V}}_{5}$ & $\overline{\mathrm{V}}_{6}$ & $\overline{\mathrm{V}}_{6}$ & $\overline{\mathrm{V}}_{1}$ & $\overline{\mathrm{V}}_{1}$ & $\overline{\mathrm{V}}_{2}$ \\
\hline & 1 & $\overline{\mathrm{V}}_{2}$ & $\overline{\mathrm{V}}_{2}$ & $\overline{\mathrm{V}}_{3}$ & $\overline{\mathrm{V}}_{3}$ & $\overline{\mathrm{V}}_{4}$ & $\overline{\mathrm{V}}_{4}$ & $\bar{V}_{5}$ & $\overline{\mathrm{V}}_{5}$ & $\bar{V}_{6}$ & $\overline{\mathrm{V}}_{6}$ & $\bar{V}_{1}$ & $\overline{\mathrm{V}}_{1}$ \\
\hline & -1 & $\overline{\mathrm{V}}_{1}$ & $\overline{\mathrm{V}}_{1}$ & $\overline{\mathrm{V}}_{2}$ & $\overline{\mathrm{V}}_{2}$ & $\overline{\mathrm{V}}_{3}$ & $\overline{\mathrm{V}}_{3}$ & $\overline{\mathrm{V}}_{4}$ & $\overline{\mathrm{V}}_{4}$ & $\bar{V}_{5}$ & $\overline{\mathrm{V}}_{5}$ & $\overline{\mathrm{V}}_{6}$ & $\overline{\mathrm{V}}_{6}$ \\
\hline & -2 & $\overline{\mathrm{V}}_{6}$ & $\overline{\mathrm{V}}_{1}$ & $\overline{\mathrm{V}}_{1}$ & $\overline{\mathrm{V}}_{2}$ & $\overline{\mathrm{V}}_{2}$ & $\overline{\mathrm{V}}_{3}$ & $\overline{\mathrm{V}}_{3}$ & $\overline{\mathrm{V}}_{4}$ & $\overline{\mathrm{V}}_{4}$ & $\overline{\mathrm{V}}_{5}$ & $\overline{\mathrm{V}}_{5}$ & $\overline{\mathrm{V}}_{6}$ \\
\hline \multirow{4}{*}{0} & 2 & $\overline{\mathrm{V}}_{3}$ & $\overline{\mathrm{V}}_{4}$ & $\overline{\mathrm{V}}_{4}$ & $\overline{\mathrm{V}}_{5}$ & $\overline{\mathrm{V}}_{5}$ & $\overline{\mathrm{V}}_{6}$ & $\overline{\mathrm{V}}_{6}$ & $\overline{\mathrm{V}}_{1}$ & $\overline{\mathrm{V}}_{1}$ & $\overline{\mathrm{V}}_{2}$ & $\overline{\mathrm{V}}_{2}$ & $\overline{\mathrm{V}}_{3}$ \\
\hline & 1 & $\overline{\mathrm{V}}_{4}$ & $\overline{\mathrm{V}}_{4}$ & $\overline{\mathrm{V}}_{5}$ & $\bar{V}_{5}$ & $\overline{\mathrm{V}}_{6}$ & $\overline{\mathrm{V}}_{6}$ & $\bar{V}_{1}$ & $\overline{\mathrm{V}}_{1}$ & $\overline{\mathrm{V}}_{2}$ & $\begin{array}{l}\overline{\mathrm{V}}_{2} \\
*\end{array}$ & $\overline{\mathrm{V}}_{3}$ & $\overline{\mathrm{V}}_{3}$ \\
\hline & -1 & $\overline{\mathrm{V}}_{7}$ & $\bar{V}_{5}$ & $\overline{\mathrm{V}}_{0}$ & $\overline{\mathrm{V}}_{6}$ & $\overline{\mathrm{V}}_{7}$ & $\overline{\mathrm{V}}_{1}$ & $\overline{\mathrm{V}}_{0}$ & $\overline{\mathrm{V}}_{2}$ & $\overline{\mathrm{V}}_{7}$ & $\overline{\mathrm{V}}_{3}$ & $\overline{\mathrm{V}}_{0}$ & $\overline{\mathrm{V}}_{4}$ \\
\hline & -2 & $\overline{\mathrm{V}}_{5}$ & $\overline{\mathrm{V}}_{6}$ & $\overline{\mathrm{V}}_{6}$ & $\overline{\mathrm{V}}_{1}$ & $\overline{\mathrm{V}}_{1}$ & $\overline{\mathrm{V}}_{2}$ & $\overline{\mathrm{V}}_{2}$ & $\overline{\mathrm{V}}_{3}$ & $\overline{\mathrm{V}}_{3}$ & $\overline{\mathrm{V}}_{4}$ & $\overline{\mathrm{V}}_{4}$ & $\overline{\mathrm{V}}_{5}$ \\
\hline
\end{tabular}

\section{EXPERIMENTAL RESULTS AND DISCUSSION}

To validate the simulation results, an experiment has been set up [7]. DSPACE card based on a Texas Instrument TMS320F2812 fixed point DSP is used. The control is transcribed in MATLAB/Simulink. The real time interface (RTI) is used to build real time code, and to download and execute this code on Dspace hardware.

For the power unit, a voltage source insulated-gate-bipolartransistor-based inverter has been used to feed the induction motor. It is based around the digital signal processor (DSP) TMS320F2812 in assembly by using the Real-Time Workshop (RTW). The Real-Time Workshop converts the Simulink block diagrams to real-time C code. This software can generate $\mathrm{C}$ code for continuous-time and discrete The eZdspTM F2812 is the link between the DSP based real-time system and the Matlab / Simulink software. This development system eZdspTM F2812 built by Spectrum Digital Inc. company. It is part of the platform C2000TM DSP, and is optimized for applications driving the induction machine. As shown, in Fig.5 (a) distortions still important but the noises in 
IM for 12_DTC are clearly decreasing.

Fig .5 (b),(c), (d) and (e) presents respectively currents, stator flux $\Phi s \alpha$ and $\Phi s \beta$, position of flux and sectors for 12_DTC, those figures shows that there is no big difference between the performances between the two strategies. Those remarks can be explained by the fact that the number of voltage vectors is not sufficient to have better precision in 12_DTC, for example in spite of using $V_{2}$ in table 3 which will give us a huge variation, we can use another voltage vector to have a small variation (we put a star for the vectors witch don't give us small variation we want).

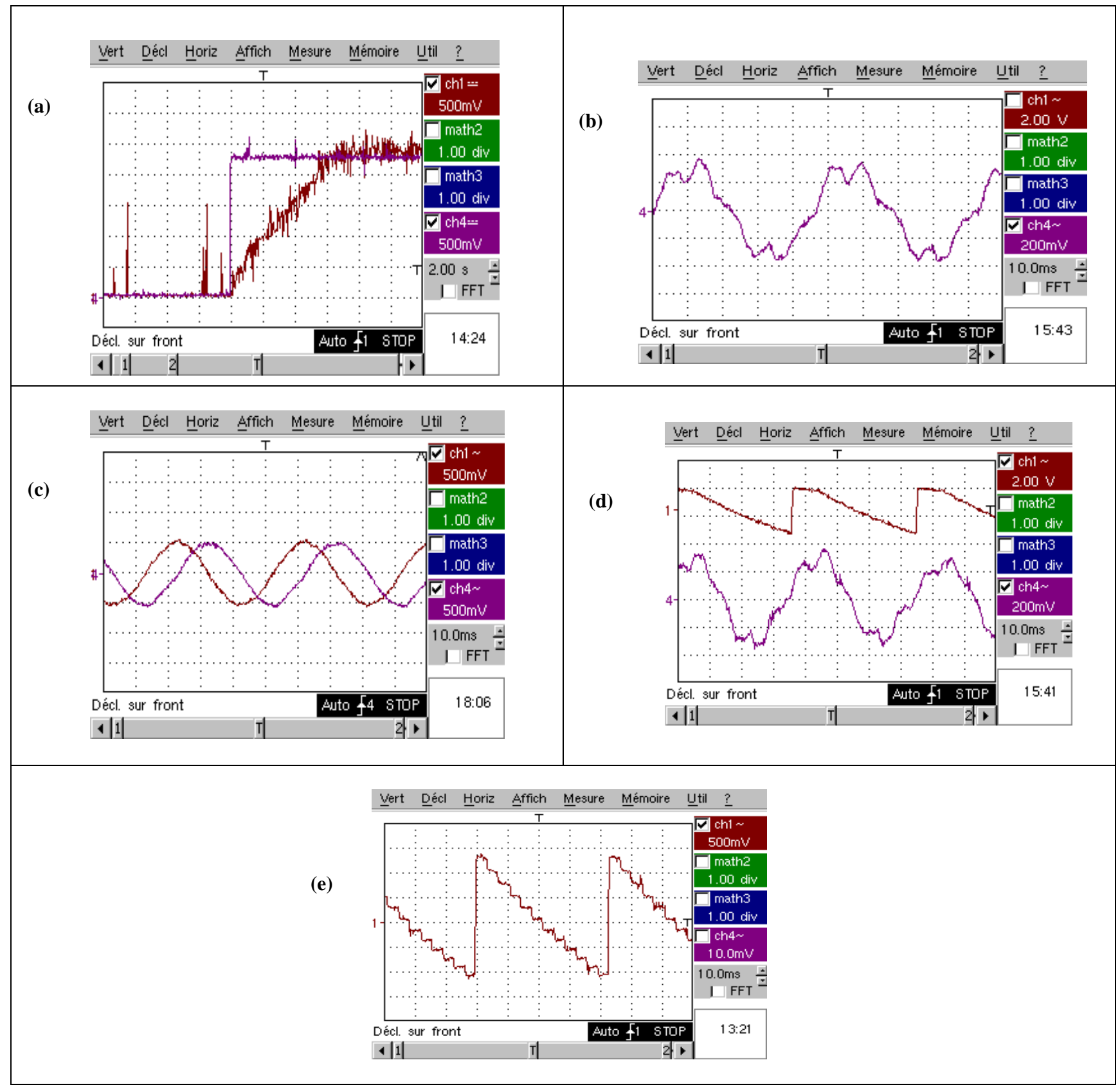

Fig. 5: Experimental results of 12_DTC : (a) torque, (b) current performances,(c) stator flux, (d) position $\theta$ s and (e) sectors.

\section{CONCLUSION}

In this paper an experimental analysis of the 12_DTC strategy have been presented. This work began by explaining the principle of the 12_DTC. The proposed models have been implemented using DSPACE board jointed with fixed point DSP, TMS320F2812. Even if the experimental results present no big improvement in term of torque distortions for 12_DTC, the noises in the IM are clearly decreasing. In fact, 12_DTC associated to a multivel inverter give the precision wanted by giving a huge number of vectors, the adequate vector is chosen to have a big or small variation and better performances will be obtained. This strategy will be tested by simulation and validated by experimentation in future works.

\section{REFERENCES}

[1] R.Ramya, A.Abhijith, SH. Raju S, M Aditya Bhat and M. Thilak "DTC and IFOC feasability analysis on torque control schemes of induction machine," Undergraduate Academic Research Journal (UARJ), ISSN: 2278 - 1129, 
Volume-2, Issue-3,4,p.4-8,2012.

[2] H.Chaikhy, M. Khafallah, A. Saad, and M. Es-saadi "Analysis of the variation effect of induction machine parametersfor vectorial control", Canadian Journal on Electrical and Electronics Engineering Vol. 2, No. 7,p.270-274, July 2011.

[3] R.Toufouti S.Meziane ,H. Benalla "Direct torque control strategies for induction machine," Acta Electrotechnica et Informatica No. 1, Vol. 7, p.1-7,2007.

[4] I. Takahashi,T. Noguchi, T: A new quickresponseand high-efficiency control strategy of induction motor, IEEE Trans. On IA, Vol.22,N .5, Sept/Oct 1986, PP.820-827.

[5] M.Essaadi, M.Khafallah, A. Saad, A. Hamdoun, H. Chaikhy,"A comparative analysis between conventionnal and new direct torque control strategies of induction
machine",IEEE proceeding 2014 Second World Conference on Complex Systems (WCCS), 350-354, , Agadir , morocco, 10-12 novembre,2014

[6] B. Mokhtari1, A. Ameur, M. F. Benkhoris, L. Mokrani1 and B. Azoui "Experimental DTC of an Induction Motor Applied to Optimize a Tracking System" International Conference on Renewable Energies and Power Quality (ICREPQ'12) Santiago de Compostela (Spain), 28th to 30th March, 2012.

[7] X. M. Chen, X. L. Gong, H. X. Zhou, Z. B. Xu, Y. G. $\mathrm{Xu}$, and C. J. Kang "An Economical Rapid Control Prototyping System Design with Matlab/Simulink and TMS320F2812 DSP" Proceeding of the international multiconference of engeneers and computer scientists 2010 Vol II, (IMECS 2010), March 17-19, Hong kong. 